\title{
The Use of Analysis of Variance of the Alpha Rhythm of the EEG in the Study of the Pathogenesis of Alcoholism and the Causes of Alcoholic Deliria
}

\author{
Rosman SV* \\ Physician of functional diagnostics of SBIH, Regional psychoneurological clinic, Russia
}

Submission: June 05, 2017; Published: June 16, 2017

*Corresponding author: Rosman SV, Physician of functional diagnostics of SBIH, Regional psychoneurological clinic, Tver, Russian Federation, Russia, Tel: +7-903-800-11-05; Email: seros2005@mail.ru

\begin{abstract}
Studied the functional ability of the neuronglial networks of the brain in patients with chronic alcoholism using a unique method of dispersion of amplitude-frequency characteristics of the alpha rhythm with the aim of studying the pathogenesis of alcoholism and delirious syndrome.

Keywords: Delirium tremens; Dispersion of amplitude-frequency characteristics of the alpha rhythm; EEG

Abbreviations: DAFCAR: Dispersion of Amplitude-Frequency Characteristics of the Alpha rhythm- EEG; NGSB: Neuron-Glial Network of the Alpha Rhythm; CD 1: The Dispersion Coefficientalpha-Rhythm-1; $\Delta$ Mf 01(02)-F3(F4): Increase (Decrease) in the Value of the Difference of Modal Frequencies Between the Occipital and Frontal Derivations; $\Delta$ F3(F4): Increase (Decrease) in the Values of the Modal Frequencies in Frontal Derivations; $\Delta \mathrm{f} 01(02)$ : Increase (Decrease) in the Values of the Modal Frequencies in Frontal Derivations; $\Delta I I D \alpha$ : Increase (Decrease) in the Value of the Integral Index of Dispersion (Kurtosis of the Normal Distribution CD $\alpha 1$ in the Occipital Leads; $\triangle$ Ad $\alpha$ : Increase (Decrease) in the Value of the Asymmetry CD 1 in the Occipital Leads; $\Delta \mathrm{IIH}$ : Increase (Decrease) in the Value of the Index Hypofrontality (Kurtosis of the Normal Distribution $\mathrm{CD} \alpha 1$ ) in the Frontal Leads; $\triangle \mathrm{AH}$ : Increase (Decrease) in the Value of the Asymmetry of CD $\alpha 1$ in the Frontal Leads
\end{abstract}

\section{Introduction}

The crisis of psychiatry is largely due to the lack of verified methods of research NGS GM, more such easily available noninvasive methods that establish the practice of governmental institutions would represent data that would be correlated with the syndromes of psychopathology and would be the basis for issuing of a correct diagnosis. This attitude on the part of clinicians fully applies to the EEG, which is considered a nonspecific method of research, i.e. research whose results cannot be compared with the observed patient's psychic-cal deviations [1].

Exactly the same attitude clinicians have to hyperventilation trial EEG, which, after a long [2] and unsuccessful attempts to use it in diagnostic mental diseases, limited to the registration of emergence or build-up and epileptiform phenomena. In the present work to analyze the effects of hyperventilation on the brain used a new, not previously used in neurophysiology to study the changes of properties of the alpha rhythm - analysis of variance of the amplitude-frequency characteristics [3-7].
The idea of this study emerged when considering the following hypothesis - psychopathology is a consequence of the in coordination activities of neuron-glial networks of the brain (NHS GM), a marker which is the disorganization of the alpha rhythm is the only rhythm of the EEG, which are manifestsuper natural ontogenetic properties. This disorganization is manifested by splitting of the spectrum of the alpha rhythm - a fact repeatedly noted by many researchers. The complexity of the practical application of this phenomenon was the lack of methods for its verification.

In the framework of solving this problem has been studied the possibility of identifying a correlation between the degree of splitting of the alpha rhythm and the ratio of the maximum power fluctuations to its total capacity throughout the range of the alpha rhythm (Figure 1A). On a large number of studies have shown that it represents the dispersion coefficient $\mathrm{CD} \alpha 1$ is back, proportional relationship with the degree of split of the alpha rhythm and the degree of severity of the Clinical manifestations of organic brain diseases. Calculating values for CD $\alpha 1$ EEG leads 
and frequencies, we placed the values obtained in the table-the matrix (Figure 1), which was the basis of the volume distribution plot of the power of the alpha rhythm in the surface of the head

(Figure 1) - this technique is called dispersion mapping of alpha rhythm.

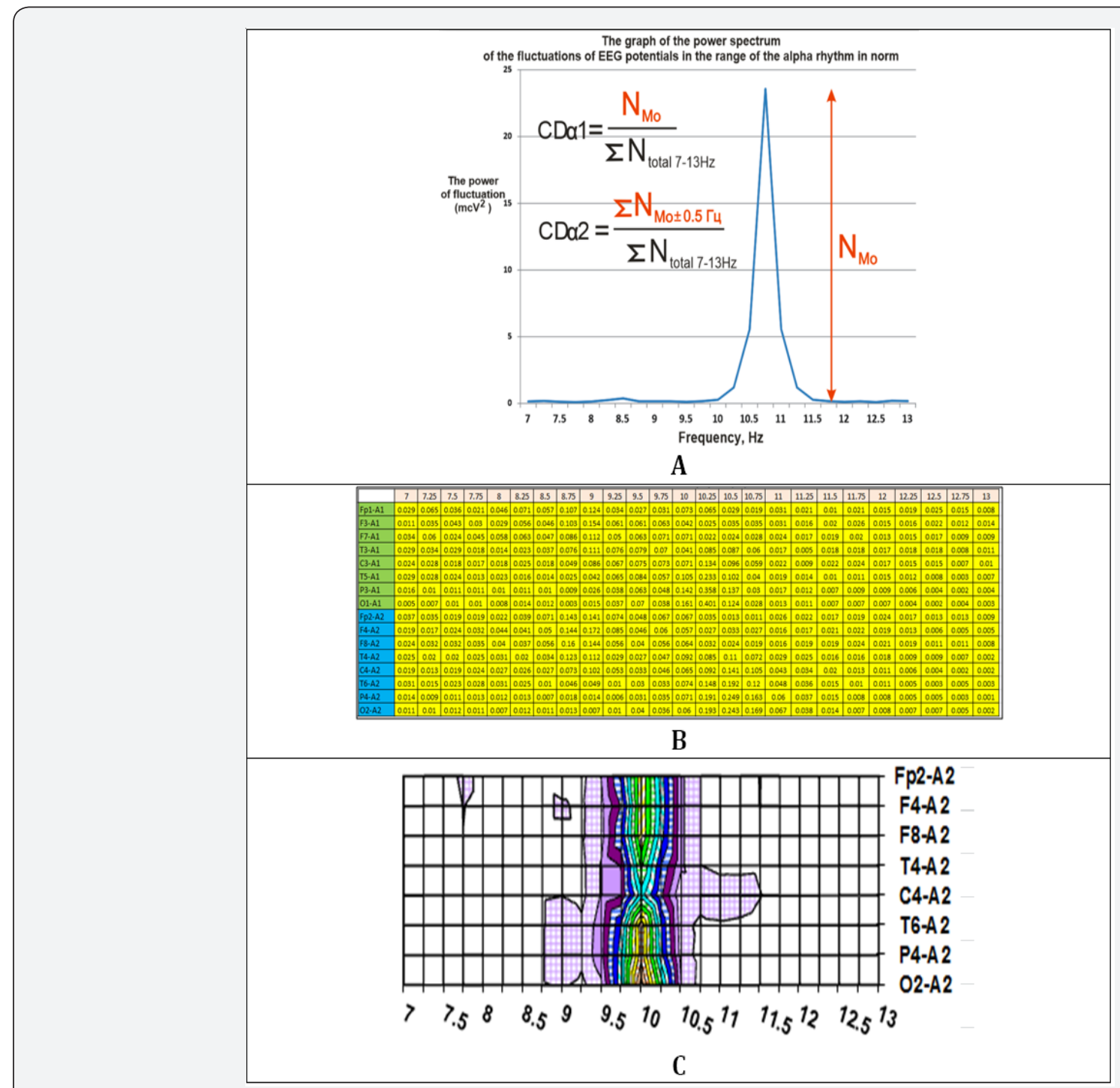

Figure 1: The sequence of the analysis of variance of the alpha rhythm.

A - calculation of values CDa1 for each lead for each value of the frequency of the alpha rhythm

$B$ - the values CDa1 in the table-matrix

C - plotting 3D graph distribution CDa1 on leads and EEG frequencies

In search of verification of dispersion changes in the alpha rhythm, we proceeded from the hypothesis that the normal distribution of the power fluctuations of EEG potentials in the range of the alpha rhythm in the spectrum is normal. The increase of entropy in the NHS GM with psychopathology leads to a splitting of the spectrum of the alpha rhythm and deviation of this distribution from normal. Thus, markers of the splitting of the alpha rhythm, along with $\mathrm{CD} \alpha 1$ are the parameters of the normal distribution - kurtosis and skewness, which are presented in the analysis of variance index of dispersion.
You should only add that in the analysis of variance of the alpha rhythm and this is very important - not investigated the distribution of the power or amplitude of the alpha rhythm and its present value is the fraction of power at a given frequency to the total power fluctuations in the alpha rhythm, which is expressed by the indicator CD $\alpha 1$. In more detail, the method of dispersion mapping and calculation of indexes of dispersion presented in the cited literature. The result of analysis of variance is given on the example of comparison of cartograms in norm and in schizophrenia (Figure 2). It should be added that the technique is simple to use, non-invasive, obtaining all parameters of dispersion and cartograms takes about 2 min [8]. 


\section{Global Journal of Addiction \& Rehabilitation Medicine}

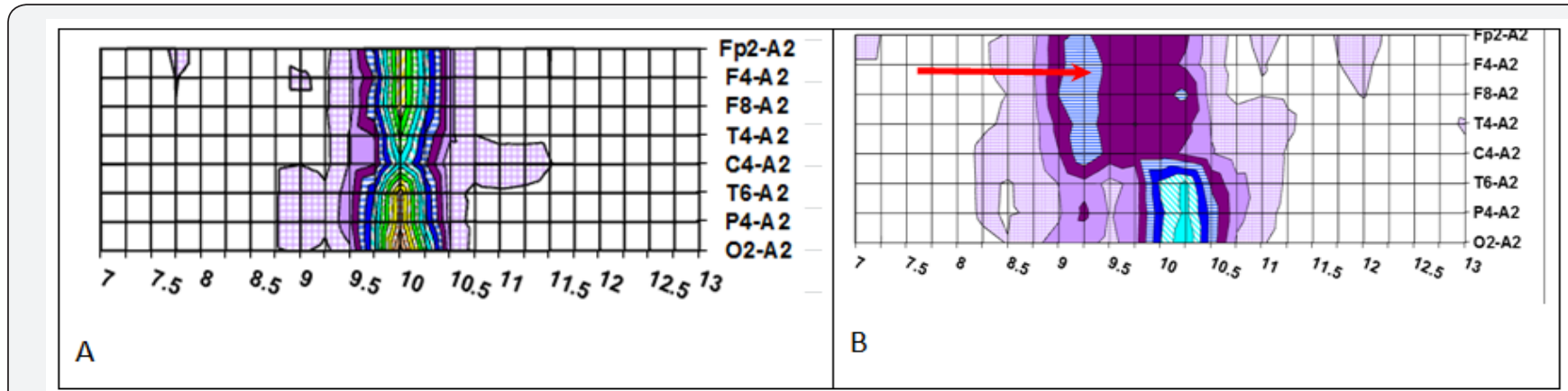

Figure 2: Comparative dispersion diagrams of the normal $(A)$ and in schizophrenia(B). Clearly visible is difficult to identify by other methods the phenomenon of functional hypofrontality(increase in dispersion and slowing of the alpha- rhythm), characteristic of schizophrenia.

\section{The purpose of the study}

Search for correlation of variance of changes of amplitudefrequency characteristics of the alpha rhythm in EEG hyperventilation test in patients with alcoholism after an alcoholic deliria.

\section{Materials and Methods}

Method of standard EEG study with the arrangement of the electrodes according to the international scheme "10-20\%" with the use of hyperventilation sample number depth of 1620 respiratory movements in $1 \mathrm{~min}$. were examined in patients with alcoholism, including undergoing delirium tremens; the control group consisted of 44 healthy young men who have the Commission of experts found no mental abnormalities. The EEG epoch with duration of 20-25 sec. in the background and after hyperventilation were subjected to spectral analysis using the fast Fourier transform by the standard method of electroencephalogram. The obtained results were exported from the device in the form of a table whose data is subjected to conversion in accordance with the method of DAFCAR. The results obtained in the form of the dispersion index and dispersion of cartograms have been studied using software Statistica 10.0, Microsoft Excel 10.0 and visual assessment of the dispersion maps to identify the type of reaction to the hyperventilation test (Table 1).

Table 1: The contingent examined by means of hyperventilation sample EEG for diseases (ICD-10) and age.

\begin{tabular}{|c|c|c|}
\hline Thediagnosticcategoryofpatients (ICD-10) & The number of patients in the sample & Average age, years \\
\hline $\begin{array}{l}\text { F10.3. Mental and behavioural disorders due to use of alcohol } \\
\text { withdrawal state }\end{array}$ & 34 & $39.6 \pm 2,1$ \\
\hline $\begin{array}{l}\text { F10.4 Mental and behavioural disorders due to use of alcohol } \\
\text { withdrawal state with delirium }\end{array}$ & 54 & $36.9 \pm 0,7$ \\
\hline Control & 44 & $20.8 \pm 0,7$ \\
\hline
\end{tabular}

a) Endogenous types were characterized by increased prevalence of spatial frequency components of alpha rhythm and increase in the number of modal zones of predominance, not of the same frequency in different region of conversation of head. This was manifested by a reduction of the modal frequency and the dispersion indices and the modal expansion zone in the direction of decreasing modal frequencies up to her disappearance on the dispersion map (Figure 3). 


\section{Global Journal of Addiction \& Rehabilitation Medicine}

b) Exogenous type was characterized by the prevalence of narrowing of the spatial frequency components of alpha rhythm with a decrease in the number of zones modal dominance and convergence of their frequency in different regions of conversation of head. This was manifested by the increase in modal frequency and the dispersion indices and the reduction of modal areas up to the establishment "of supersynchronous" on the dispersion map (Figure 4).
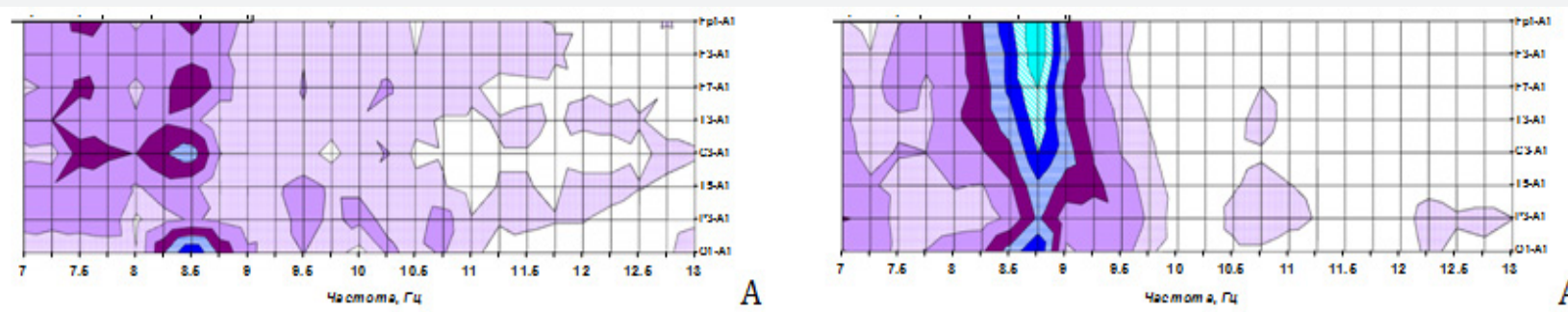

c) Neutral type characterized by the absence of changes in the key dispersion parameters of amplitude-frequency characteristics of the alpha rhythm and the unchanged pattern of dispersion diagrams (Figure 5).
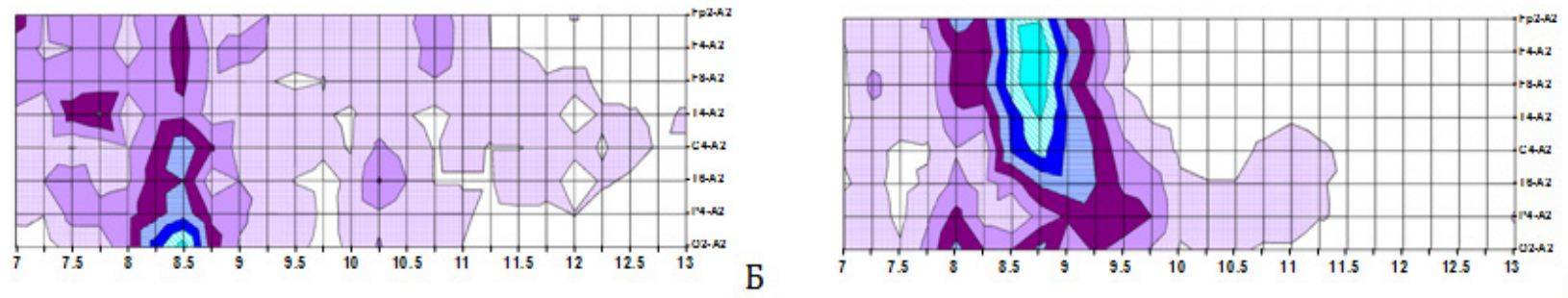

Figure 3: type Endogenous changes in the dispersion of cartograms on the results of hyperventilation EEG samples. Left - background cartogram on the right - cartogram after hyperventilation. A-left hemisphere and B - right hemisphere.
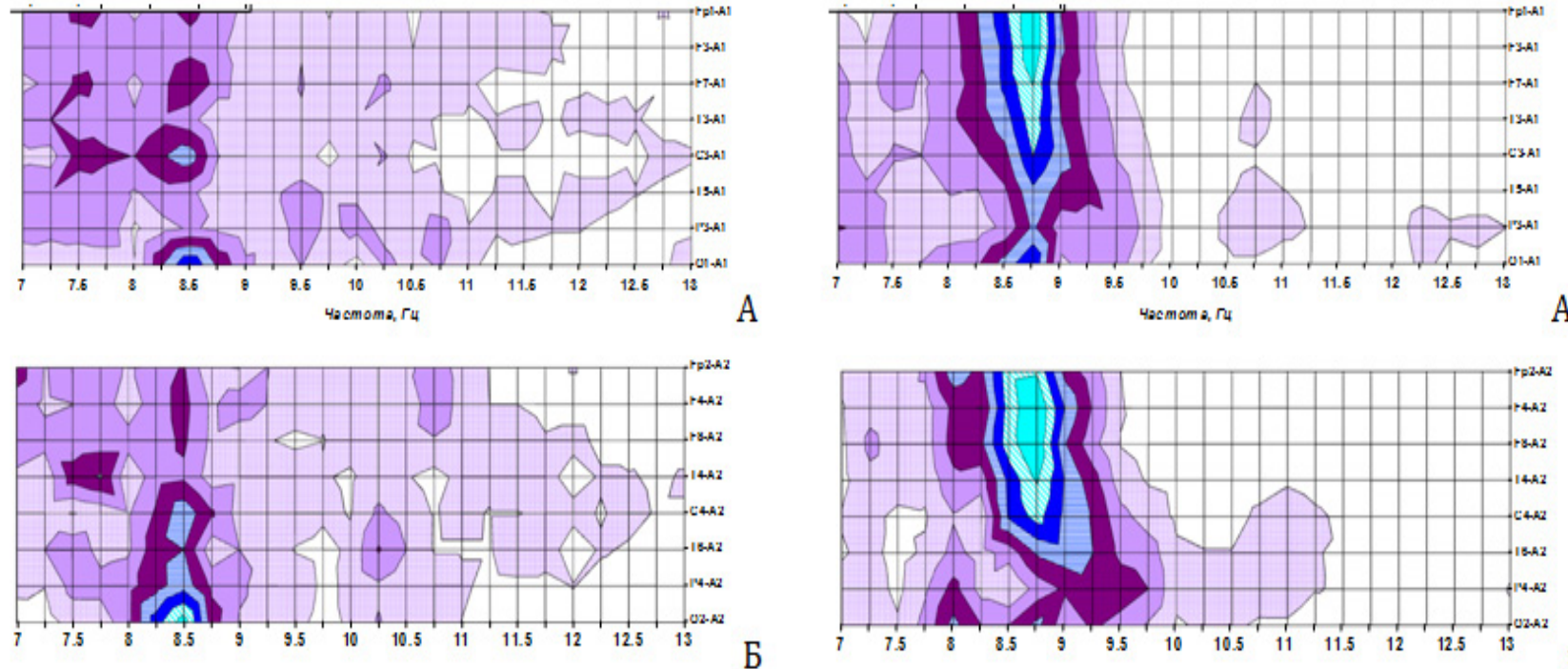

Figure 4: Exogenous changes in the dispersion type cartograms according to the results of hyperventilation EEG samples. Left - background cartogram on the right - cartogram after hyperventilation. A-left hemisphere and B - right hemisphere. 
Table 2: The results of variance analysis of changes of amplitude-frequency characteristics after Hyper-ventilation tests, the left hemisphere (the numerator is the mean value, the denominator is the confidence interval $\pm 95 \%$ ).

\begin{tabular}{|c|c|c|c|c|c|}
\hline Nosological form & $\begin{array}{l}\text { The indicator in } \\
\text { the sample }\end{array}$ & $\begin{array}{l}\text { Endogeneous } \\
\text { type }\end{array}$ & Exogeneous type & Neutral type & Mixed type \\
\hline \multirow{6}{*}{$\begin{array}{l}\text { F10.3. Mental and } \\
\text { behavioural disorders due } \\
\text { to use of alcohol withdrawal } \\
\text { state }\end{array}$} & $\Delta \mathrm{Mf} 01-\mathrm{F} 3$ & $\begin{array}{c}-0.75 \\
-1.36--0.14\end{array}$ & $\begin{array}{c}0.821 \\
0.27-1.37\end{array}$ & $\begin{array}{c}0 \\
-0.37-0.37\end{array}$ & $\begin{array}{c}2.625 \\
-8.49-13.74\end{array}$ \\
\hline & $\Delta \mathrm{F} 3$ & $\begin{array}{c}0.725 \\
0.16-1.29\end{array}$ & $\begin{array}{c}-0.661 \\
-1.27--0.05\end{array}$ & $\begin{array}{c}0.125 \\
-0.29-0.54\end{array}$ & $\begin{array}{c}-0.375 \\
-5.14-4.39\end{array}$ \\
\hline & $\Delta \mathrm{f} 01$ & $\begin{array}{c}-0.025 \\
-0.74-0.69\end{array}$ & $\begin{array}{c}0.161 \\
-0.15-0.47\end{array}$ & $\begin{array}{c}0.125 \\
-0.12-0.37\end{array}$ & $\begin{array}{c}2.25 \\
-4.1-8.6\end{array}$ \\
\hline & $\Delta \mathrm{IID} \alpha$ & $\begin{array}{c}2.401 \\
0.59-4.21\end{array}$ & $\begin{array}{c}0.089 \\
-1.72-1.89\end{array}$ & $\begin{array}{c}-0.323 \\
-3.76-3.11\end{array}$ & $\begin{array}{c}-0.849 \\
-10.39-8.7\end{array}$ \\
\hline & $\Delta \mathrm{AD} \alpha$ & $\begin{array}{c}0.621 \\
0.07-1.18\end{array}$ & $\begin{array}{c}0.129 \\
-0.31-0.57\end{array}$ & $\begin{array}{c}-0.066 \\
-0.89-0.76\end{array}$ & $\begin{array}{c}-0.175 \\
-4.24-3.89\end{array}$ \\
\hline & $\Delta \mathrm{IIH}$ & $\begin{array}{c}2.55 \\
0.19-4.91\end{array}$ & $\begin{array}{c}-2.508 \\
-3.58--1.44\end{array}$ & $\begin{array}{c}1.22 \\
-0.14-2.58\end{array}$ & $\begin{array}{c}5.816 \\
-18.78-30.42\end{array}$ \\
\hline \multirow{8}{*}{$\begin{array}{l}\text { F10.4 Mental and } \\
\text { behavioural disorders } \\
\text { due to use of alcohol } \\
\text { withdrawal state with } \\
\text { delirium }\end{array}$} & $\Delta \mathrm{AH}$ & $\begin{array}{c}0.6 \\
-0.03-1.23\end{array}$ & $\begin{array}{c}-0.719 \\
-1.01-0.43\end{array}$ & $\begin{array}{c}0.204 \\
-0.13-0.54\end{array}$ & $\begin{array}{c}1.141 \\
0.36-1.92\end{array}$ \\
\hline & $\Delta \mathrm{Mf} 01-\mathrm{F} 3$ & $\begin{array}{c}-0.897 \\
-1.29--0.5\end{array}$ & $\begin{array}{c}0.977 \\
0.28-1.67\end{array}$ & $\begin{array}{c}-0.048 \\
-0.21-0.12\end{array}$ & $\begin{array}{c}0.35 \\
-1.13-1.83\end{array}$ \\
\hline & $\Delta \mathrm{F} 3$ & $\begin{array}{c}0.603 \\
0.11-1.1\end{array}$ & $\begin{array}{c}-0.591 \\
-1.08--0.1\end{array}$ & $\begin{array}{c}-0.012 \\
-0.13-0.11\end{array}$ & $\begin{array}{c}-0.05 \\
-1.36-1.26\end{array}$ \\
\hline & $\Delta \mathrm{f} 01$ & $\begin{array}{c}-0.294 \\
-0.69-0.1\end{array}$ & $\begin{array}{c}0.386 \\
-0.1-0.88\end{array}$ & $\begin{array}{c}-0.06 \\
-0.22-0.1\end{array}$ & $\begin{array}{c}0.3 \\
-1.11-1.71\end{array}$ \\
\hline & $\Delta \mathrm{IID} \alpha$ & $\begin{array}{c}1.895 \\
-0.11-3.9\end{array}$ & $\begin{array}{c}-0.46 \\
-2.09-1.17\end{array}$ & $\begin{array}{c}0.703 \\
-0.71-2.11\end{array}$ & $\begin{array}{c}-1.029 \\
-8.21-6.16\end{array}$ \\
\hline & $\Delta \mathrm{AD} \alpha$ & $\begin{array}{c}0.419 \\
-0.11-0.95\end{array}$ & $\begin{array}{c}-0.175 \\
-0.61-0.26\end{array}$ & $\begin{array}{c}0.205 \\
-0.13-0.54\end{array}$ & $\begin{array}{c}-0.256 \\
-1.72-1.21\end{array}$ \\
\hline & $\Delta \mathrm{IIH}$ & $\begin{array}{c}2.416 \\
1.12-3.71\end{array}$ & $\begin{array}{c}-2.317 \\
-3.54--1.1\end{array}$ & $\begin{array}{c}0.396 \\
-0.23-1.02\end{array}$ & $\begin{array}{c}1.857 \\
-1.11-4.83\end{array}$ \\
\hline & $\Delta \mathrm{AH}$ & $\begin{array}{c}0.652 \\
0.27-1.03\end{array}$ & $\begin{array}{c}-0.428 \\
-0.84--0.02\end{array}$ & $\begin{array}{c}0.103 \\
-0.08-0.29\end{array}$ & $\begin{array}{c}0.35 \\
-0.13-0.83\end{array}$ \\
\hline \multirow{7}{*}{ Control } & $\Delta \mathrm{Mf}$ 01-F3 & - & $\begin{array}{c}-0.045 \\
-0.11-0.02\end{array}$ & $\begin{array}{c}-0.008 \\
-0.06-0.05\end{array}$ & - \\
\hline & $\Delta \mathrm{F} 3$ & - & $\begin{array}{c}-0.045 \\
-0.17-0.08\end{array}$ & $\begin{array}{c}-0.156 \\
-0.23--0.08\end{array}$ & - \\
\hline & $\Delta \mathrm{f} 01$ & - & $\begin{array}{c}-0.091 \\
-0.23-0.04\end{array}$ & $\begin{array}{c}-0.164 \\
-0.23--0.1\end{array}$ & - \\
\hline & $\Delta \mathrm{IID} \alpha$ & - & $\begin{array}{c}-1.341 \\
-3.01-0.33\end{array}$ & $\begin{array}{c}0.695 \\
-0.24-1.63\end{array}$ & - \\
\hline & $\Delta \mathrm{AD} \alpha$ & - & $\begin{array}{c}-0.138 \\
-0.4-0.12\end{array}$ & $\begin{array}{c}0.125 \\
-0.01-0.26\end{array}$ & - \\
\hline & $\Delta \mathrm{IIH}$ & - & $\begin{array}{c}-3.475 \\
-4.17--2.78\end{array}$ & $\begin{array}{c}0.686 \\
0.13-1.24\end{array}$ & - \\
\hline & $\Delta \mathrm{AH}$ & - & $\begin{array}{c}-0.507 \\
-0.61--0.41\end{array}$ & $\begin{array}{c}0.123 \\
0.02-0.22\end{array}$ & - \\
\hline
\end{tabular}


Table 3: The results of variance analysis of changes of amplitude-frequency characteristics after Hyper-ventilation tests, the right hemisphere (the numerator is the mean value, the denominator is the confidence interval $\pm 95 \%$ ).

\begin{tabular}{|c|c|c|c|c|c|}
\hline Nosological form & $\begin{array}{l}\text { The indicator in } \\
\text { the sample }\end{array}$ & Endogeneous type & $\begin{array}{l}\text { Exogeneous } \\
\text { type }\end{array}$ & $\begin{array}{l}\text { Neutral } \\
\text { type }\end{array}$ & Mixed type \\
\hline \multirow{7}{*}{$\begin{array}{l}\text { F10.3. Mental and } \\
\text { behavioural disorders due } \\
\text { to use of alcohol withdrawal } \\
\text { state }\end{array}$} & $\Delta$ Mf 01-F3 & $\begin{array}{c}-0.563 \\
-1.14-0.02\end{array}$ & $\begin{array}{c}0.525 \\
0.04-1.01\end{array}$ & $\begin{array}{c}0.212 \\
0.05-0.37\end{array}$ & $\begin{array}{c}-0.583 \\
-5.75-4.59\end{array}$ \\
\hline & $\Delta \mathrm{F} 3$ & $\begin{array}{c}0.625 \\
-0.12-1.37\end{array}$ & $\begin{array}{c}-0.35 \\
-0.97-0.27\end{array}$ & $\begin{array}{c}-0.135 \\
-0.34-0.08\end{array}$ & $\begin{array}{c}0.417 \\
-5.22-6.05\end{array}$ \\
\hline & $\Delta \mathrm{f} 01$ & $\begin{array}{c}0.063 \\
-0.62-0.75\end{array}$ & $\begin{array}{c}0.175 \\
-0.23-0.58\end{array}$ & $\begin{array}{c}0.077 \\
-0.1-0.26\end{array}$ & $\begin{array}{c}-0.167 \\
-1.12-0.78\end{array}$ \\
\hline & $\Delta \mathrm{IID} \alpha$ & $\begin{array}{c}-1.744 \\
-2.78--0.71\end{array}$ & $\begin{array}{c}1.59 \\
-1.3-4.48\end{array}$ & $\begin{array}{c}0.507 \\
-1.5-2.52\end{array}$ & $\begin{array}{c}2.134 \\
-3.55-7.82\end{array}$ \\
\hline & $\Delta \mathrm{AD} \alpha$ & $\begin{array}{c}-0.455 \\
-0.7--0.21\end{array}$ & $\begin{array}{c}0.291 \\
-0.38-0.96\end{array}$ & $\begin{array}{c}0.164 \\
-0.32-0.65\end{array}$ & $\begin{array}{c}0.375 \\
-0.41-1.16\end{array}$ \\
\hline & $\Delta \mathrm{IIH}$ & $\begin{array}{c}3.964 \\
0.71-7.22\end{array}$ & $\begin{array}{c}-2.896 \\
-4.17--1.62\end{array}$ & $\begin{array}{c}1.314 \\
0.12-2.51\end{array}$ & $\begin{array}{c}-0.953 \\
-8.09-6.19\end{array}$ \\
\hline & $\Delta \mathrm{AH}$ & $\begin{array}{c}0.857 \\
0.2-1.52\end{array}$ & $\begin{array}{c}-0.754 \\
-1.04--0.47\end{array}$ & $\begin{array}{c}0.274 \\
0.03-0.51\end{array}$ & $\begin{array}{c}-0.332 \\
-2.98-2.31\end{array}$ \\
\hline \multirow{7}{*}{$\begin{array}{l}\text { F10.4 Mental and } \\
\text { behavioural disorders } \\
\text { due to use of alcohol } \\
\text { withdrawal state with } \\
\text { delirium }\end{array}$} & $\Delta$ Mf 01-F3 & $\begin{array}{c}-0.797 \\
-1.41--0.18\end{array}$ & $\begin{array}{c}1.117 \\
0.41-1.82\end{array}$ & $\begin{array}{c}0.028 \\
-0.13-0.19\end{array}$ & $\begin{array}{c}-0.45 \\
-3.27-2.37\end{array}$ \\
\hline & $\Delta \mathrm{F} 3$ & $\begin{array}{c}0.453 \\
0.2-0.7\end{array}$ & $\begin{array}{c}-0.717 \\
-1.3--0.13\end{array}$ & $\begin{array}{c}-0.222 \\
-0.45-0.01\end{array}$ & $\begin{array}{c}0.95 \\
-0.16-2.06\end{array}$ \\
\hline & $\Delta \mathrm{fO} 1$ & $\begin{array}{l}-0.344 \\
-1-0.31\end{array}$ & $\begin{array}{c}0.4 \\
-0.1-0.9\end{array}$ & $\begin{array}{c}-0.194 \\
-0.43-0.04\end{array}$ & $\begin{array}{c}0.5 \\
-1.86-2.86\end{array}$ \\
\hline & $\Delta \mathrm{IID} \alpha$ & $\begin{array}{c}1.969 \\
-0.08-4.02\end{array}$ & $\begin{array}{c}-0.337 \\
-1.94-1.27\end{array}$ & $\begin{array}{l}-0.208 \\
-1.7-1.28\end{array}$ & $\begin{array}{c}1.604 \\
-2.67-5.88\end{array}$ \\
\hline & $\Delta \mathrm{AD} \alpha$ & $\begin{array}{c}0.465 \\
-0.03-0.96\end{array}$ & $\begin{array}{c}0.032 \\
-0.47-0.53\end{array}$ & $\begin{array}{c}-0.04 \\
-0.4-0.32\end{array}$ & $\begin{array}{c}0.4 \\
-0.71-1.51\end{array}$ \\
\hline & $\Delta \mathrm{IIH}$ & $\begin{array}{c}1.703 \\
0.02-3.39\end{array}$ & $\begin{array}{c}-2.718 \\
-4--1.43\end{array}$ & $\begin{array}{c}1.035 \\
0.36-1.71\end{array}$ & $\begin{array}{c}-2.232 \\
-8.54-4.07\end{array}$ \\
\hline & $\Delta \mathrm{AH}$ & $\begin{array}{c}0.5 \\
0.06-0.94\end{array}$ & $\begin{array}{c}-0.623 \\
-0.94--0.3\end{array}$ & $\begin{array}{c}0.192 \\
-0.02-0.41\end{array}$ & $\begin{array}{c}-0.684 \\
-2.43-1.06\end{array}$ \\
\hline \multirow{7}{*}{ Control } & $\Delta$ Mf 01-F3 & - & $\begin{array}{c}-0.045 \\
-0.11-0.02\end{array}$ & $\begin{array}{c}-0.008 \\
-0.06-0.05\end{array}$ & - \\
\hline & $\Delta \mathrm{F} 3$ & - & $\begin{array}{c}-0.045 \\
-0.17-0.08\end{array}$ & $\begin{array}{c}-0.156 \\
-0.23--0.08\end{array}$ & - \\
\hline & $\Delta \mathrm{fO} 1$ & - & $\begin{array}{c}-0.091 \\
-0.23-0.04\end{array}$ & $\begin{array}{c}-0.164 \\
-0.23--0.1\end{array}$ & - \\
\hline & $\Delta \mathrm{IID} \alpha$ & - & $\begin{array}{c}-1.341 \\
-3.01-0.33\end{array}$ & $\begin{array}{c}0.695 \\
-0.24-1.63\end{array}$ & - \\
\hline & $\Delta \mathrm{AD} \alpha$ & - & $\begin{array}{c}-0.138 \\
-0.4-0.12\end{array}$ & $\begin{array}{c}0.125 \\
-0.01-0.26\end{array}$ & - \\
\hline & $\Delta \mathrm{IIH}$ & - & $\begin{array}{c}-3.475 \\
-4.17--2.78\end{array}$ & $\begin{array}{c}0.686 \\
0.13-1.24\end{array}$ & - \\
\hline & $\Delta \mathrm{AH}$ & - & $\begin{array}{c}-0.507 \\
-0.61--0.41\end{array}$ & $\begin{array}{c}0.123 \\
0.02-0.22\end{array}$ & - \\
\hline
\end{tabular}


d) The mixed type was not clearly defined signs of the first two types. Along with quality rendered the methods of the study variance a change has been studied the changes of variance of indicators (indexes) of the alpha rhythm of the EEG after conducting a hyperventilation test. Hemispheres and type of response they were not statistically significant differences (Tables $2 \& 3$ ).

A very important point is the fact that the changes of the dispersion index reflect the changes that we have seen in the dispersion maps thus, the possible verification of these qualitative assessments. The General features of the changes in the index of dispersion in the result of hyperventilation samples, depending on the type of reaction are:

a. The increase of dispersion of the alpha rhythm endogenous reaction is accompanied by a decrease $\Delta$ Mf 01 F3 down to negative values; all other indices are increasing (have a positive value). On the map at the same time expanding the area of representation of the alpha rhythm predominantly in the frontal leads

b. Reduced dispersion of the alpha rhythm is the exogenous reaction is accompanied by an increase in $\Delta \mathrm{Mf}$ 01-F3 up to positive values; all other indexes are decreasing (have negative value). On the cartogram the reduced zone representation of the alpha rhythm.

c. Neutral type of reaction is accompanied by minimal change in the indices of dispersion: \pm 0.25 of the original value.

d. Mixed reaction type - different combinations of changes in the index of the most various kinds, sometimes of large amplitude, often associated with concomitant severe vascular, toxic, traumatic changes of a regional nature.

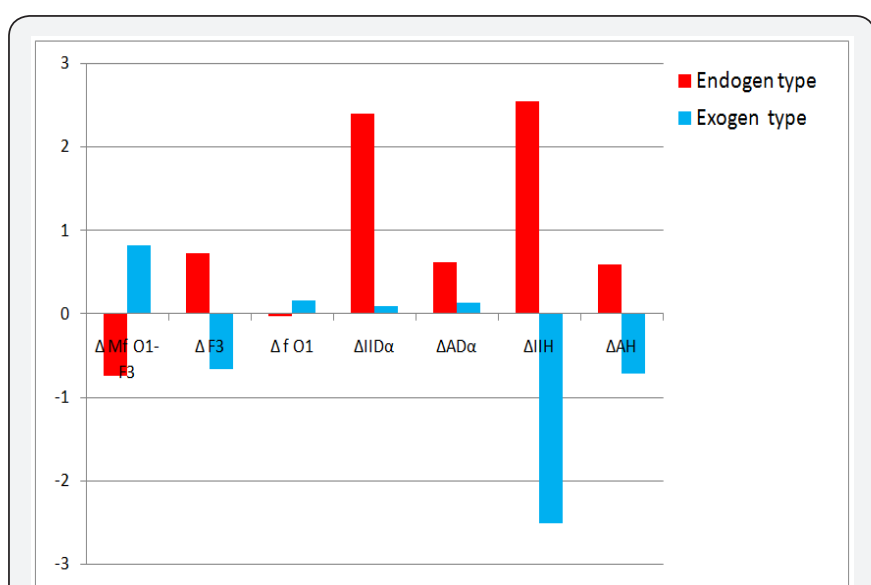

Figure 6: The direction of changes in the dispersion after hyperventilation, the left hemisphere (F10.3).

Thus, changes of indexes of dispersion in reactions of endogenous and exogenous types are diametrically opposed in nature. More clearly the different directions of these changes are shown in Figures $6 \&$ 7. In connection with the inaccuracy of the differences between the hemispheres presents only the data of the left hemisphere.

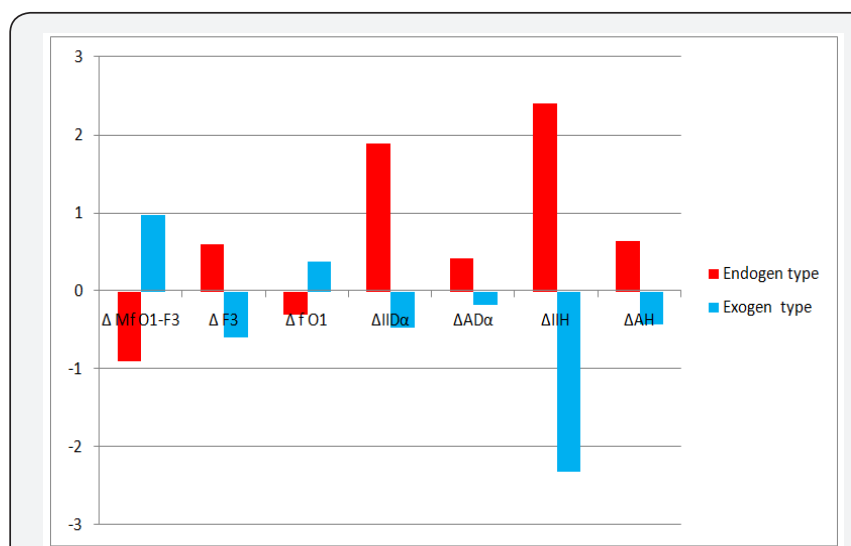

Figure 7: The direction of changes in the dispersion after hyperventilation, the left hemisphere (F10.4).

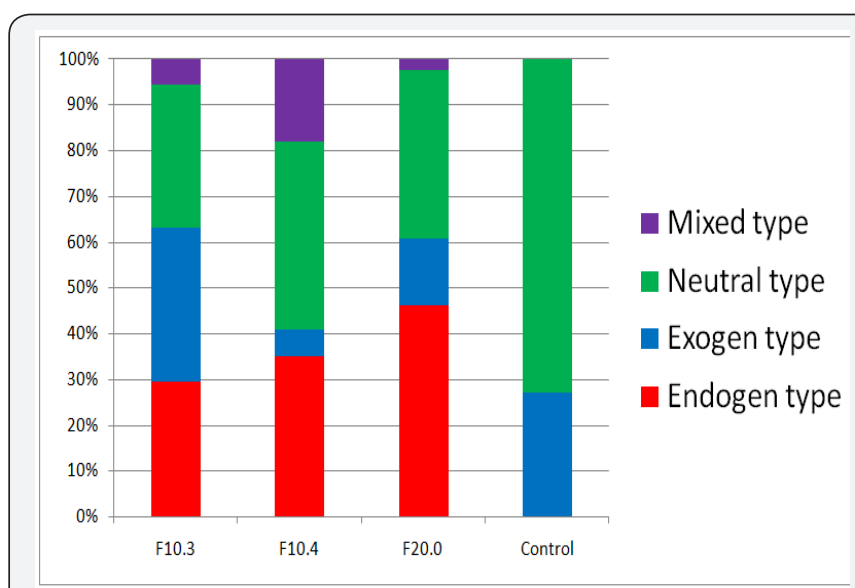

Figure 8: The distribution of types of responses hyperventilation on diagnostic categories, the left hemisphere F10.3. Mental and behavioural disorders due to use of alcohol withdrawal state

F10.4 Mental and behavioural disorders due to use of alcohol withdrawal state with delirium

F20-F29. Schizophrenia, schizotypal and delusional disorders.

It is established that identified the types of reactions on the GW-test, in addition to verified the statistically significant parameters in the change of indexes of dispersion of the alpha rhythm and visual indication of the dispersion map, and had some correlation matching with the character of the course of alcoholism. Endogenous type more often seen among sufferers of alcoholism withdrawal syndrome with delirium; an exogenous and neutral type - among patients with uncomplicated withdrawal syndrome; mixed type are more characteristic of alcoholism with comorbid organic diseases. It should be noted that a similar reaction to the hyperventilation characteristic of all diseases that occur with delusional syndrome (F20) - (Figures $8 \& 9)$. 


\section{Global Journal of Addiction \& Rehabilitation Medicine}

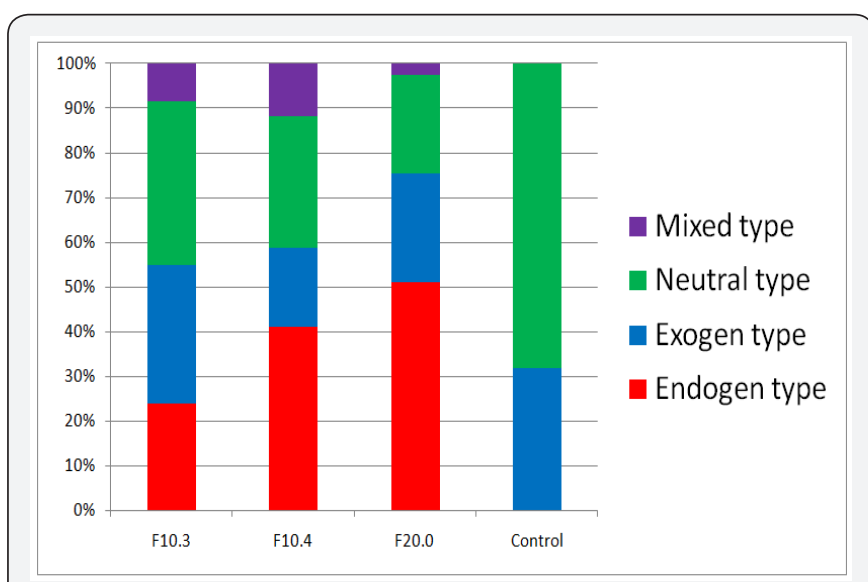

Figure9: The distribution of types of responses hyperventilation on diagnostic categories, the right hemisphere.

\section{Discussion}

Well-known polietiologic changes in the brain in alcoholism. In this paper the author addresses a General aspect of the problem associated with the disorder of NGSB. Particularly interesting revealed relationship with endogenous diseases of schizophrenic circle, that allows to suspect a common mechanism underlying how addictive and schizoid disease defect NGSB, which perversely responds to stress - endogenous reaction, which reflects the process of increasing disruption of its activities. Illustrative is the increase of signs of functional hypofrontality, which acts as a marker of pronounced behavioral disorders, up to delusional. Perhaps this feature of NGSB, the GM determines addictological problems in alcoholics. Identification of the endogenous response to hyperventilation can be a serious prognostic-a sign to those in the subclinical stage of the disease. Open remains the question of whether the response to hyperventilation due to the constitutional property of the NGSM, or that acquired property - a phenomenon described before in the medical practice is not described.

One thing is certain - the study of the phenomenon of dispersion of the alpha rhythm opens new perspectives in the understanding of brain activity and the socio-biological consequences of the disruption of the functional capacity of NGS. Undoubtedly, such a generalization can be done after extensive research, but this work does not claim to final conclusions. The purpose of this publication is to show that the application of
DAFCAR, including functional tests, EEG, expands the diagnostic capabilities in psychiatry in General and in addictolagy in particular. The most important is the fact that psychiatry using methods similar to the dispersion analysis of alpha-rhythm is transformed from a categorical, descriptive discipline into a modern science, standing on the rails of evidence-based medicine.

\section{Conclusion}

The use of analysis of variance of amplitude-frequency characteristics of the alpha- rhythm in EEG hyperventilation test allows identifying and verifying specific functional features of the neural network of the brain in various forms of mental illness, including alcoholism. The identification of belonging of the investigated neural networks to a specific type according to the results of the GW test is an objective method and can be used in early diagnosis of the patient's propensity to complicated forms of the course of alcoholism and the study of the pathogenesis of delusional syndrome.

\section{References}

1. Davis H, Wallace W (1972) Factors affecting changes produced in the electroencephalogram by standardized hyperventilation. Arch Neuropsychol 47: 606.

2. Gibbs FA, Davis H, Lennox, WG (1935) The electroencephalogram in epilepsy and in conditions of impaired consciousness. Arch Neurol Psychiatry 34(6): 1133-1148.

3. Maksimova NE, Rosman SV, Shpak LV, Zabodaev SV (2016) Possibilities of use of dispersion of an alpha rhythm for screening verification of mental diseases. Psikh zdorov'e 1: 16-25.

4. Rosman SV (2013) Diagnostic capabilities of dispersion mapping the alpha rhythm of the electroencephalogram. Psikh zdorov'e 6: 64-69. (In Russ).

5. Rosman SV (2013) Opportunities of the dispersive mapping of the alpha rhythm of electroencephalogram in diagnostics of schizophrenia. Psikhiatriya 2: 32-37. (In Russ).

6. Rosman SV (2013) Use of $\alpha$-rhythm dispersion mapping in the early detection of mental illnesses. Vrach. 8: 79-82. (In Russ).

7. Rosman SV, Shpak LV (2013) Newapproaches to the assessment of polymorphism of the alpha rhythm EEG in psychiatric disorders. Psikh. zdorov'e 2: 39-44. (In Russ).

8. Sanislow Charles A (2013) Updating the Research Domain Criteria. World Psychiatry 15(3): 222-223.

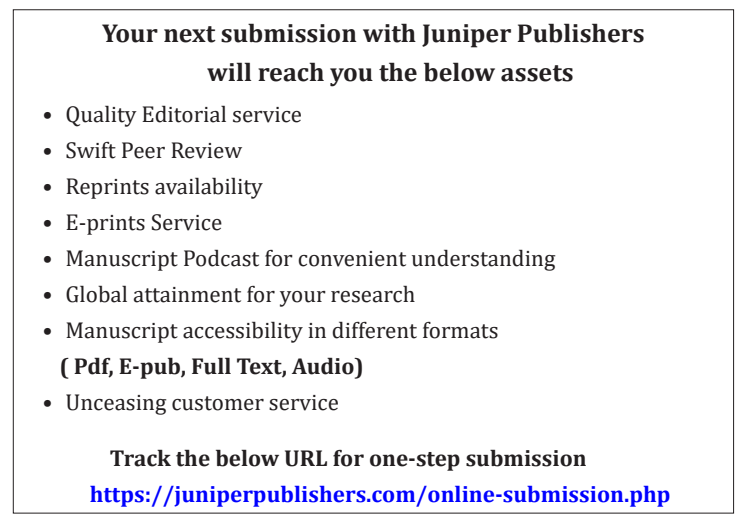

